\title{
DETECÇÃO REMOTA \\ E SISTEMAS DE INFORMAÇÃO GEOGRÁFICA \\ PARA PRODUÇÃO DE CARTOGRAFIA \\ DE USO E OCUPAÇÃO DO SOLO
}

JORGE ROCHA ${ }^{1}$

\begin{abstract}
Resumo-A principal finalidade da metodologia apresentada neste documento é a criação e a validação, através da aplicação a um caso de estudo, de uma forma eficiente de classificação de imagens de satélite, que integra informação auxiliar (dados dos Censos, do Plano Director Municipal e a rede viária) e dados provenientes de Detecção Remota, num Sistema de Informação Geográfica. O procedimento desenvolvido segue uma estratégia de classificação por níveis, sendo composto por três etapas principais: Estratificação pré-classificação; Aplicação dos classificadores de Bayes e de Máxima Verosimilhança (MV); Aplicação de regras de pós-classificação. As abordagens comuns incorporam os dados auxiliares antes, durante ou depois da classificação. No método proposto recorre-se a esse tipo de informação em todas as etapas. O método consegue, globalmente, melhores resultados que os classificadores clássicos: Mínima Distância, Paralelepípedo e Máxima Verosimilhança (MV). Além disso, melhora substancialmente a exactidão das classes onde o processo de classificação faz uso da informação auxiliar.
\end{abstract}

Palavras-chave: Sistemas de Informação Geográfica (SIG), detecção remota, informação auxiliar.

Abstract-REMOTE SENSING AND GEOGRAPHIC INFORMATION SYSTEMS IN THE PRODUCTION OF LAND USE MAPS. The main purpose of this research is to develop and validate an efficient form of satellite image classification that integrates ancillary information (Census data; the Municipal Master Plan; the Road Network) and remote sensing data in a Geographic Information System. The developed procedure follows a layered classification approach, comprising three main stages: Pre-classification stratification; Application of Bayesian and Maximum-likelihood classifiers; Post-classification sorting. Common approaches incorporate the ancillary data before, during or after classification. In the proposed method, all the steps take the ancillary information into account. The proposed method achieves, much better classification results than the classical, one layer, Minimum Distance and Maximum-likelihood (ML) classifiers. Also, it greatly improves the accuracy of those classes where the classification process uses the ancillary data.

Key words: Geographic Information Systems (GIS), remote sensing, ancillary data.

1 Investigador do Centro de Estudos Geográficos e Assistente da Faculdade de Letras da Universidade de Lisboa. E-mail: jrocha@fl.ul.pt 
Résumé - UTILISATION DE LA TÉLÉDÉTECTION ET DES SYSTÈMES D’INFORMATION GÉOGRAPHIQUE DANS LA CARTOGRAPHIE D'UTILISATION ET D'OCCUPATION DES SOLS. On cherche à montrer, par une étude de cas, comment créer et valider une technique efficace de classification des images de satellite, en y intégrant des informations auxiliaires (données des recensements, des plans directeurs municipaux et du réseau routier). On applique une stratégie de classification par niveaux, en trois étapes: Stratification pré-classificatoire; Application des classificateurs de Bayes et de Vraisemblance Maximale (MV); Règles de post-classification. En général, les données auxiliaires sont introduites avant, pendant ou après la classification. La technique proposée permet d'y recourir au cours de toutes les étapes, ce qui améliore tant les résultats que l'exactitude de la définition des classes.

Mots-clés: Systèmes d’Information Géographique (SIG), télédétection, information auxiliaire.

\section{INTRODUÇÃO}

As imagens de satélite são, desde o seu aparecimento, tidas como um poderoso meio de obter informação actualizada, a custos relativamente baixos, sobre as actividades que decorrem em meio urbano, incluindo aquelas que se processam na franja urbano-rural. O seu formato de dados permite a utilização de algoritmos de classificação automática e/ou semi-automática viabilizando, assim, uma análise mais célere, menos dispendiosa e espectralmente mais abrangente do que no caso das fotografias aéreas.

Várias abordagens têm sido levadas a efeito para identificar e medir, de forma automática ou semi-automática, as diferentes características do espaço urbano, tendo-se chegado a resultados muito diversos. De facto, se para os estudos que incidem sobre áreas agrícolas o processamento digital de imagens tem provado o seu valor, quando se faz a transposição para áreas construídas os resultados já não são tão eloquentes (SADLER e BARNSLEY, 1990).

A resolução espacial das imagens serviu, inicialmente, como justificação para todos os problemas encontrados, sendo indicada como o principal factor limitativo em diversos estudos (WELCH, 1982). Contudo, alguns autores (CAETANO et al., 1997) têm feito notar que, paradoxalmente, o aumento da resolução espacial pode conduzir a maiores problemas no tratamento numérico de imagens, em função da grande heterogeneidade espectral do meio urbano, que conduz implicitamente a um aumento da variabilidade e, consequentemente, do designado "ruído». À medida que a resolução espacial aumenta, os detalhes da imagem (ex. estradas, casas) vão tomando forma, e adquirindo uma certa predominância na resposta espectral de cada pixel, promovendo um tratamento erróneo e confuso, comprometendo a extracção de informação global e tornando difícil uma classificação coerente e homogénea da imagem. Na realidade, as áreas urbanas envolvem classes de uso espectralmente heterogéneas, tornando impraticável uma correcta classificação das imagens, com base unicamente em informação espectral (MARTIN et al., 1988). 
Os Sistemas de Informação Geográfica (SIG) permitem a fácil integração de informação proveniente de diversas fontes. Este facto pode ser explorado na classificação de imagens de satélite, através da utilização de informação não espectral (também designada de auxiliar ou colateral).

Até ao presente, somente alguns trabalhos integraram dados dos Censos na classificação das imagens de satélite. Um dos mais recentes, foi realizado em Portugal pelo Centro Nacional de Informação Geográfica (CNIG) em parceria com o Instituto Nacional de Estatística (INE). Este estudo (CAETANo et al., 1997) visava avaliar a dinâmica do crescimento da área da grande Lisboa, usando dados espectrais (imagens SPOT) e auxiliares (Rede viária, Modelos Digitais do Terreno - MDT - e os Censos). A metodologia seguida utilizou o MDT para a correcção dos efeitos topográficos nas imagens, a Rede Viária para, numa fase de pré-classificação, estratificar a imagem (filtro urbano/não urbano) e os dados dos Censos relativos aos alojamentos para o desenvolvimento de regras de pós-classificação. Em 1998, outro trabalho de relevo (MESEv, 1998), utilizou os dados dos edifícios existentes nos Censos para definir a priori a probabilidade de ocorrência de determinadas classes de uso de solo, recorrendo a um classificador de Bayes, e cruzando essas probabilidades com a classificação de imagens de satélite (Landsat ETM+).

Nesta abordagem combinam-se as probabilidades espectrais calculadas pelo método da máxima verosimilhança com uma outra superfície de probabilidade (a priori) obtida, ou não, a partir de técnicas de detecção remota. Estas probabilidades, estabelecidas antecipadamente, podem ser interpretadas como um meio de deslocação das fronteiras de decisão, por forma a criar, num espaço de medição, de $n$ dimensões, maiores volumes para classes que se esperam de grande dispersão e volumes mais pequenos para as de dispersão mais diminuta. Começam por determinar-se as probabilidades a priori para cada classe. Por exemplo, ao considerar-se uma área hipotética onde a probabilidade de se encontrar o uso 'urbano' é de 0,3 e a de encontrar o uso 'praia' é de 0,1 , seria de esperar que mais pixels fossem classificados como 'urbano' (numa relação de 3 para 1) simplesmente porque este uso tem uma maior prevalência no terreno. Esta informação a priori pode ser incluída na regra de classificação, ponderando cada classe com a sua probabilidade a priori, ao contrário do algoritmo de máxima verosimilhança que assume uma probabilidade de ocorrência igual para todas as classes.

A metodologia apresentada neste artigo pode considerar-se um desenvolvimento destes dois trabalhos. Neste contexto, propõe-se a apresentação dos resultados de um projecto que teve por objectivo o desenvolvimento e validação, numa área de teste, de uma forma melhorada de classificação de imagens que integra, em ambiente SIG, dados provenientes dos Censos e de Detecção Remota. Esta metodologia foi testada numa área com 2,3km por $4 \mathrm{~km}$, nas imediações do Estádio Nacional, concelho de Oeiras. 


\section{INFORMAÇÃO UTILIZADA}

Para se atingirem os objectivos propostos recorreu-se a várias fontes de informação que se podem dividir em dois grande grupos: o da informação auxiliar e o das imagens provenientes de sensores orbitais. No primeiro caso, utilizou-se a informação disponibilizada pela Planta de Ordenamento (ratificada em 1994) do Plano Director Municipal (PDM) de Oeiras, pela rede viária (1998), e pelo Instituto Nacional de Estatística (INE), esta descriminada à subsecção estatística (Base Geográfica de Referenciação de Informação - BGRI) e correspondente ao Recenseamento Geral da População de 2001. Os Censos incluem uma vasta quantidade de informação estatística, dividida em quatro subgrupos: famílias, alojamentos, indivíduos, e edifícios. Tendo em conta anteriores experiências (WEBER e HiRSCH, 1992; MESSEV et al., 1996), foi feita uma primeira selecção de informação (Quadro I).

A rede viária e a planta de ordenamento do PDM foram seleccionadas porque, no caso da primeira, já existia em formato vectorial e portanto não fazia sentido recorrer às imagens de satélite para extrair uma informação já disponível e que podia ser inserida na classificação final com uma exactidão de 100\%. Para além disso, a inclusão da rede viária permite retirar da classificação das imagens de satélite uma classe (rede viária) que tem grandes semelhanças (pelos níveis radiométricos semelhantes) com a habitação plurifamiliar, e que, ao ser retirada, permite calcular com melhor exactidão esta última, pois deixa de haver confusão entre as duas. Quanto à planta de ordenamento do PDM, foi seleccionada porque, muito embora as classes de ordenamento que nela estão representadas sejam predominantemente indicadoras do uso/ocupação possível, também existem classes que representam os usos existentes na altura da elaboração do plano, permitindo a elaboração de regras de pós-classificação, com o objectivo de melhorar o resultado da classificação das imagens de satélite.

\section{Quadro I - Informação estatística seleccionada em primeira instância}

$$
\text { Table I - First selection of Census data }
$$

\section{CAMPOS}

Número de Alojamentos Familiares Número de Alojamentos Clássicos Número de Alojamentos Colectivos prisões, etc.

Número de Indivíduos Residentes

Total de Edifícios (clássicos)

Edifícios por data de construção Edifícios por número de Pavimentos Edifícios exclusivamente Residenciais Edifícios principalmente residenciais Edifícios principalmente não residenciais

\section{DESCRIÇÃo}

Todos os que se albergam pelo menos uma família. Alojamentos integrados em edifícios clássicos.

Hotéis e similares, lares de terceira idade, conventos, hospitais,

Todos os indivíduos que habitam na subsecção (estivessem ou não presentes no momento do recenseamento).

A sua estrutura e materiais empregues são de natureza não precária (duração prevista de pelo menos 10 anos)

Edifícios destinados exclusivamente a habitação Edifícios destinados principalmente a habitação

Edifícios destinados principalmente a funções não residenciais 
Relativamente aos dados espectrais, optou-se por utilizar a banda pancromática ( $15 \mathrm{~m}$ de pixel) Landsat ETM + e todas as bandas multiespectrais $(30 \mathrm{~m}$ de pixel, com excepção da banda 6 que foi excluída devido à sua menor resolução espacial-60m), obtidas a 27 de Julho de 2000. Esta opção deve-se ao facto de se pretender juntar a melhor resolução espacial da imagem pancromática, com a superior resolução espectral das restantes bandas.

\section{PROCESSAMENTO DA INFORMAÇÃO AUXILIAR}

Nesta fase do trabalho, realizaram-se todas as operações relacionadas com o tratamento estatístico dos dados, incluindo o cálculo das probabilidades de ocorrência a priori das classes de uso do solo. Os dados apurados permitiram ainda a criação de uma banda contextual a introduzir futuramente na classificação das imagens de satélite, possibilitaram a definição de um primeiro mapa binário traduzindo os usos urbano e não urbano (máscara urbana inicial), e viabilizaram a criação de uma máscara que permitiu segmentar todas as imagens em 'água' e 'não água' (máscara água/não água).

Para a criação da máscara água/não água, optou-se por uma segmentação hierárquica, de forma a individualizar a mancha urbana. Começou por se retirar a área da imagem que corresponde ao rio Tejo, ou seja, a parte identificada como água. Foi neste passo que se fez pela primeira vez uso da informação não espectral (integração pré-processamento), na medida em que, muito embora os classificadores tradicionais consigam quase sempre identificar os pixels em questão com uma precisão de aproximadamente $100 \%$, não resolvem o problema dos que apresentam uma mistura de vários usos (nomeadamente junto à costa), conhecidos habitualmente como mixels.

Nestas situações, é comum pixels da linha de costa serem classificados como água, e vice-versa; esta questão foi resolvida, neste caso, com o recurso ao ficheiro gráfico da delimitação das subsecções, que apresenta o limite de costa perfeitamente definido (não existem subsecções estatísticas dentro de água) e que foi transformado num ficheiro matricial binário, em que a área ocupada por água tinha valor 0 e a restante 1 . Assim, recorrendo às leis da álgebra booleana foi possível, multiplicando todas as imagens por esta máscara, extrair todas as áreas de água.

No passo seguinte, procedeu-se a uma análise mais cuidada da informação estatística seleccionada, tendo em atenção os objectivos a atingir. Com efeito, na primeira escolha realizada tinha sido incluída informação relativa aos indivíduos (WEBER e Hirsch, 1992) e aos alojamentos (CAETANO et al., 1997). Estes subgrupos foram considerados desnecessários, ou mesmo inutilizáveis, para o cálculo das probabilidades a priori, na medida em que não permitem uma clara relação com a resposta espectral dos objectos urbanos. Assim, a partir da primeira selecção de dados, fez-se uma segunda escolha, optando-se apenas pela informação relativa ao subgrupo 'Edifícios', na medida em que era possível calcular as probabilidades de todas as classes que se pretendia identificar e 
também, dado que se reporta aos edifícios, conter informação que pode mais eficazmente ser correlacionada com a reflectância. Isto porque os satélites, ao registar informação reflectida pela superfície terrestre, também recolhem informação sobre os edifícios, ao contrário do que acontecia relativamente aos alojamentos que, por se encontrarem no interior dos edifícios, são «invisíveis» para os satélites.

O tratamento propriamente dito dos dados estatísticos começou com a sua ordenação de forma crescente, que permitiu deste logo identificar as subsecções onde não existiam edifícios e, que, portanto, não são urbanas. Assim, estas subsecções 'não urbanas' foram imediatamente excluídas da BGRI, uma vez que como se pretendia aplicar o algoritmo de Bayes apenas às áreas urbanas, não fazia sentido elas estarem representadas no mapa (BGRI) que iria servir de base ao cálculo das probabilidades a priori.

Retirando da BGRI as subsecções 'não urbanas' (ou rurais) deu-se o primeiro passo no sentido de criar um ficheiro que constituísse uma diferenciação entre o urbano e o rural. O ficheiro com as subsecções rurais foi unificado com a rede viária, que está integrada no tecido urbano, mas efectivamente não o é, dando origem à primeira máscara urbano-rural (máscara urbana inicial). De seguida seleccionaram-se as classes que poderiam ser calculadas com recurso ao classificador de Bayes, já que as suas probabilidades de ocorrência $a$ priori também podiam ser estimadas. As classes consideradas foram «Núcleo Antigo», "Comércio e Serviços», «Habitação Unifamiliar» e «Habitação Plurifamiliar». Posto isto, foi necessário estabelecer as fórmulas de cálculo das probabilidades de ocorrência das quatro classes acima mencionadas, o que obrigou à definição de alguns conceitos iniciais: habitação plurifamiliar, habitação unifamiliar e núcleo antigo.

Assim, os edifícios com mais de dois pisos (pavimentos) foram considerados habitação plurifamiliar, e os de um ou dois pisos habitação unifamiliar. O núcleo antigo ${ }^{2}$ foi estabelecido como o conjunto de edifícios construídos até 1945, inclusivamente. Depois de calculadas estas quatro probabilidades para todas as subsecções (excepto aquelas que tinham 0 edifícios), passou-se à fase final deste bloco de operações. Nesta fase, foi possível, recuperando alguma informação que tinha sido descartada no processo de cálculo das probabilidades (densidade populacional, densidade de edifícios, percentagem de edifícios unifamiliares e plurifamiliares) e através de uma análise de clusters, criar uma ima-gem que traduz as áreas estruturantes do território em análise, constituindo uma banda de informação contextual.

2 Esta opção deveu-se ao facto de o núcleo antigo delimitado na Carta de Uso do Solo da AML para 1991 (que poderia servir de ficheiro de validação) corresponder à mancha de construído em 1940 e de nesta década ter havido uma alteração no tipo de materiais de construção utilizados, facto que também é perceptível através das imagens de satélite e que, portanto, permite uma grande correlação entre os dois tipos de dados (estatísticos e espectrais). 
No entanto, e face à pouca expressividade dos dendrogramas produzidos pela análise de clusters, esta nova banda foi criada de forma a estabelecer apenas três grandes grupos de subsecções (subsecções fortemente urbanizadas, subsecções pouco urbanizadas e subsecções com pouca probabilidade de terem edifícios). Por fim, para que esta classificação em clusters fosse útil ao processo de classificação espectral os pixels de cada uma das três classes foram substituídos pelos valores médios das classes espectrais correspondentes.

\section{METODOLOGIA DE CLASSIFICAÇÃO}

A metodologia de classificação desenvolvida segue uma abordagem por níveis (layers), sendo composta por três fases principais: 1) Estratificação Pré-classificação; 2) Aplicação dos classificadores de Bayes e da Máxima Verosimilhança e 3) Aplicação de Regras Pós-classificação. Normalmente, as abordagens tradicionais utilizam a informação auxiliar numa destas fases.

O método proposto, destaca-se da generalidade dos métodos existentes porque a informação auxiliar é utilizada em todas as três fases de classificação.

\section{Estratificação Pré-classificação}

O objectivo desta fase é produzir, como dados de entrada para o classificador, três estratos principais - 'água', 'áreas urbanas' e 'áreas não urbanas' que serão processados individualmente. Na fase de pré-processamento já tinha sido produzida uma máscara binária terra/água, que permitiu extrair de todas as bandas (imagens de satélite e banda urbana contextual) a ocupação 'água', e uma primeira aproximação à máscara binária urbano/não urbano (máscara urbana inicial). Nesta fase é produzida uma versão mais correcta desta máscara.

O procedimento de pré-classificação, que é esquematizado na figura 1, consiste na aplicação de um algoritmo de auto-organização iterativa (Iterative Self Organising Data Analysis Technique) - ISODATA - a um conjunto de informação formado pelas bandas espectrais, a banda contextual urbana e pelas duas bandas TVI (Transformed Vegetation Index) obtidas para cada grupo de imagens de satélite (SPOT e Landsat). Estes índices de vegetação representam a quantidade de biomassa existente à superfície, contribuindo bastante para a diferenciação urbano/não urbano. A razão que esteve na base da escolha do algoritmo ISODATA (semelhante ao K-means) relaciona-se com dois factores: i) a intenção de, nesta fase, identificar classes espectrais e não classes de uso e ii) o conhecimento transmitido por trabalhos anteriores (GONG e HOWARTH, 1990) assinalando que a conjugação deste algoritmo com uma banda contextual (similar à usada neste trabalho) pode melhorar os resultados da classificação até $10 \%$. O TVI foi utilizado devido à sua forte correlação com a densidade de construção (JAYAMANNA, 1996) e a sua capacidade para melhorar a descriminação das áreas urbanas (ACHEN, 1992). 
O melhor resultado (em termos de maximizar a discriminação entre áreas construídas e não construídas) foi obtido pela classificação em seis clusters. Reclassificando esta imagem, criou-se uma nova máscara urbano/não urbano (máscara urbana intermédia) que ao ser intersectada com a 'máscara urbana inicial' deu origem à 'mascara urbana final'.

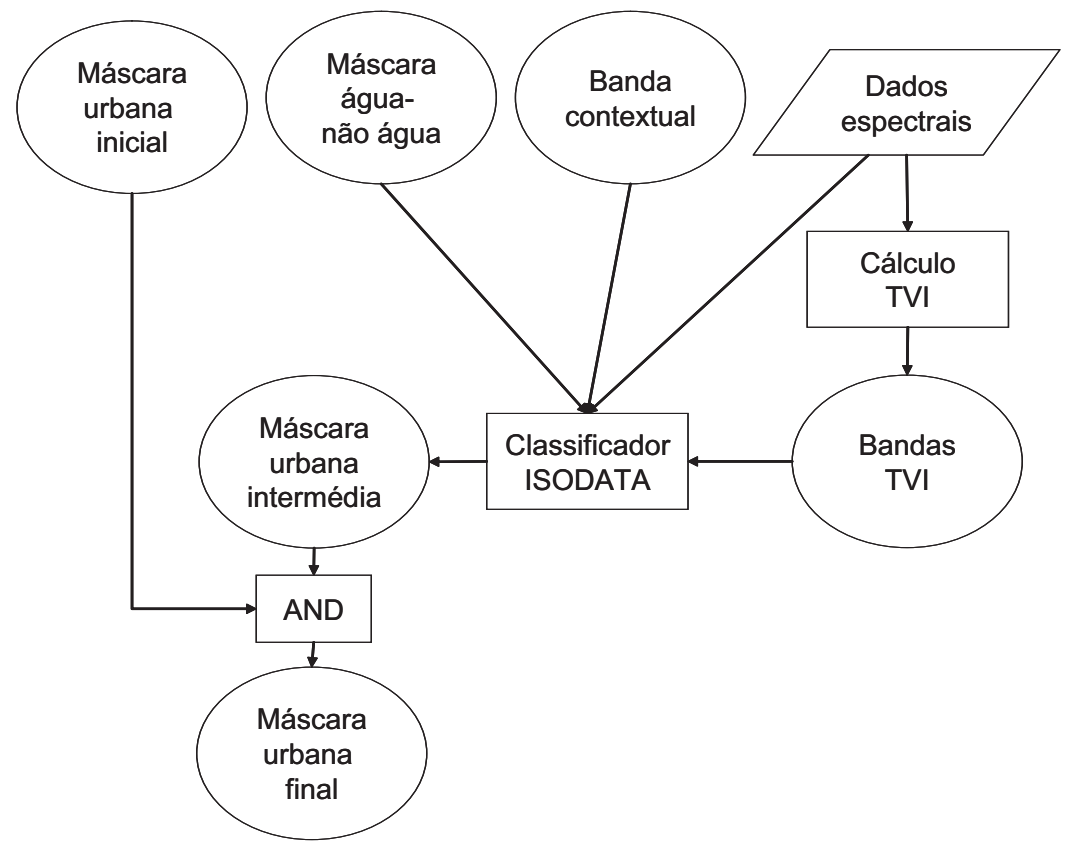

Fig. 1 - Diagrama esquemático dos processos efectuados na fase de estratificação préclassificação

Fig. 1 - Schematic diagram of pre-classification stratification

A obtenção sucessiva das três máscaras (Quadro II) permitiu uma melhoria progressiva na diferenciação urbano/rural, como demonstram as exactidões globais ${ }^{3}$ de $48 \%$ para a 'máscara urbana inicial', $80 \%$ para a 'máscara urbana intermédia' e 93\% para a 'máscara urbana final'.

Na máscara urbana inicial todas as áreas assinaladas como não urbanas eram-no efectivamente, mas existia uma grande percentagem de áreas assinalas

3 A exactidão global é obtida dividindo o número total de pixels correctamente classificados (a soma dos elementos da diagonal) pelo número total de pixels existentes na imagem de referência. Da mesma forma, a exactidão de cada categoria pode ser obtida através do quociente entre os pixels correctamente classificados de uma categoria e o número total de pixels da linha ou coluna correspondente. 
como urbanas que não correspondiam a essa classe. Com a criação da máscara urbana intermédia, identificaram-se as áreas espectralmente tidas como urbanas. Neste caso, tornou-se, de uma maneira geral, mais fácil distinguir entre o urbano e o não urbano, mas perdeu-se algum pormenor em certas áreas. A última máscara (máscara urbana final) apresenta uma melhoria de resultados em relação à anterior (máscara urbana intermédia) em virtude do seu cruzamento com a máscara urbana inicial ter permitido a extracção da rede viária e das áreas que embora espectralmente sejam classificadas como urbanas o não sejam seguramente, pois possui-se o conhecimento prévio de que lá não existem edifícios. O exemplo mais pertinente é o do areeiro situado a Noroeste na imagem que estava classificado como urbano na máscara urbana intermédia e que foi praticamente eliminado da máscara urbana final.

Ainda relativamente à qualidade dos dados, refira-se que a máscara urbana intermédia, calculada sem a banda contextual atingiu uma exactidão de $83,4 \%$, e a mesma máscara estimada sem recurso às duas bandas TVI alcançou apenas $76,2 \%$. Daqui se retira que a utilização do índice de vegetação constitui efectivamente uma mais valia para a metodologia desenvolvida $(8,5 \%)$, e que a banda contextual, embora introduzindo alguns melhoramentos $(1,3 \%)$, pode não constituir uma opção válida quando se entra em consideração com a relação, entre o tempo de (pré)processamento e a qualidade dos resultados.

Quadro II - Exactidão global (EG) para as três máscaras produzidas Table II - Global accuracy for the three created masks

Exactidão Global (\%)

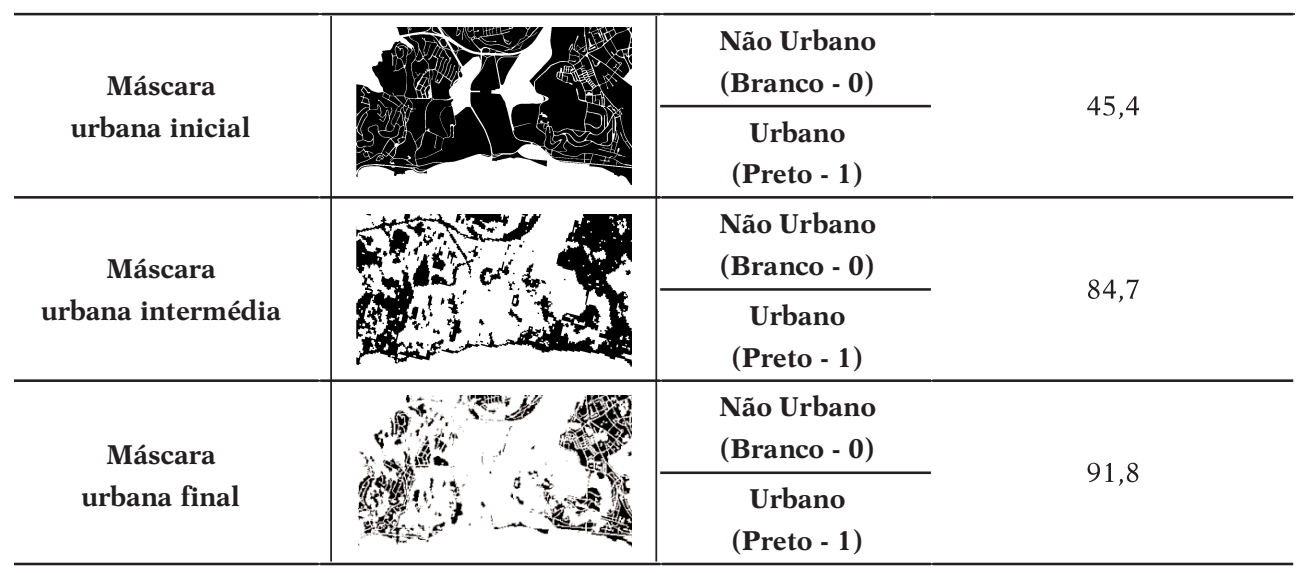

\section{Aplicação dos classificadores de Bayes e de Máxima Verosimilhança (MV)}

A segunda fase do processo de classificação é esquematicamente representada na figura 2. As máscaras binárias urbana (máscara urbana final) e de água 
(máscara água/não água), obtidas nas fases anteriores, são cruzadas com todas as bandas espectrais, produzindo duas novas imagens para cada uma das originais: uma para usos não urbanos (Mata, Mato, Solo a Nu, Agricultura, Vias e Grandes Equipamentos) e urbanos (Comércio e Serviços, Núcleo Urbano Antigo, Habitação Plurifamiliar, Habitação Unifamiliar, Indústria, Grandes Equipamentos).

Os usos 'Mata', 'Mato', 'Solo a Nu' e 'Agricultura', pertencentes às imagens não urbanas, foram extraídos recorrendo a um classificador de Máxima Verosimilhança (MV). Note-se que, como referido, a classe 'vias' já estava disponível em formato vectorial. A 'praia' e os 'grandes equipamentos' não urbanos serão obtidos no próximo passo de classificação, recorrendo à planta de ordenamento do PDM e a regras de pós-classificação.

O passo seguinte na persecução dos objectivos propostos correspondeu à aplicação de um algoritmo de Bayes sobre o conjunto das imagens urbanas, de forma a serem obtidas as probabilidades espectrais de cada classe de uso urbano. Para esse efeito, recorreu-se a uma opção que permite transformar este classificador num algoritmo flexível, ou seja, em vez de produzir uma classificação rígida e final de cada pixel, fornece várias imagens correspondentes ao grau de confiança (espectral) com que um pixel é atribuído a uma determinada classe.

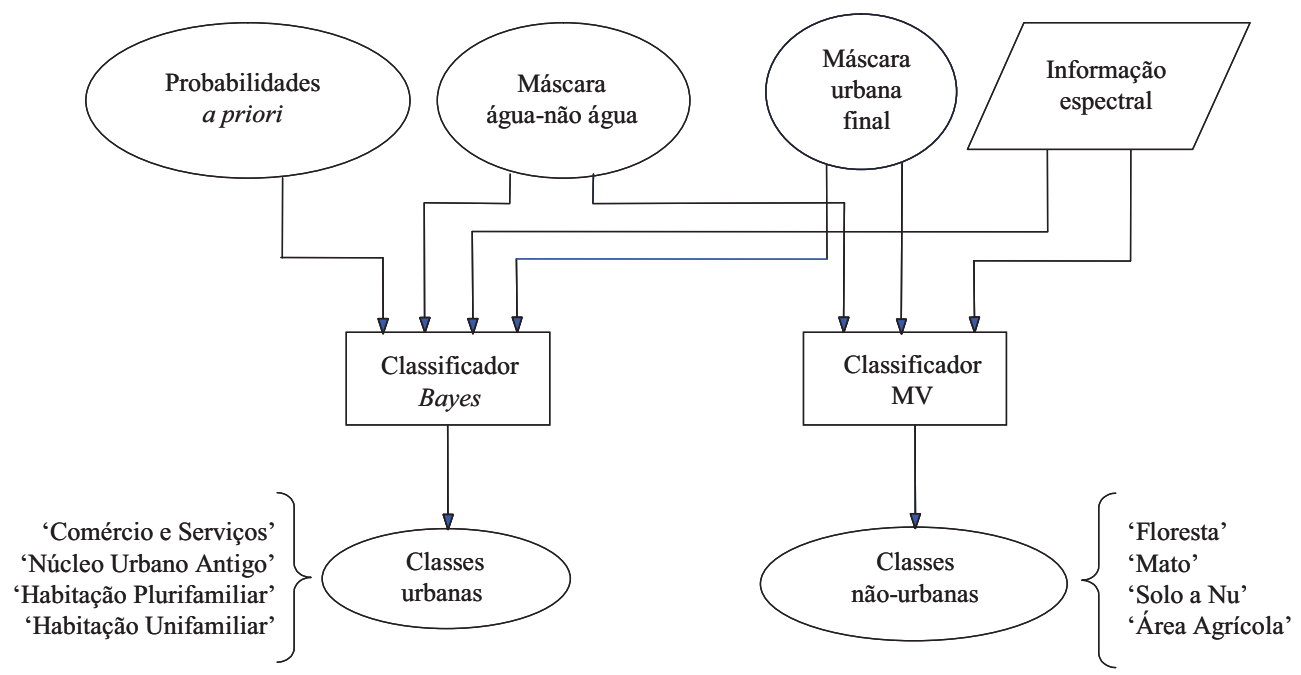

Fig. 2 - Representação esquemática dos processos de classificação (Bayes e MV)

Fig. 2 - Schematic representation of classification processes (Bayes and $M L$ )

Por sua vez, as probabilidades a priori são apresentadas como uma imagem e reportando-se à área geográfica delimitada pela máscara urbana final, existindo uma para cada classe de uso urbano. Neste processo, os edifícios exclusiva 
ou principalmente destinados a fins residenciais, com mais de dois pisos, foram considerados alojamentos plurifamiliares. Os edifícios exclusiva ou principalmente considerados para fins residenciais, com um ou dois pisos, foram considerados alojamentos unifamiliares. Os núcleos antigos urbanos foram incluídos nos edifícios construídos até 1945, inclusive. De facto, nos anos 40 ocorreu uma alteração no tipo de materiais utilizados na construção, facto que é perceptível nas imagens de satélite, o que permite uma correlação bastante significativa entre dois tipos de dados (espectrais e estatísticos). Os edifícios de comércio e serviços foram considerados como estando incluídos nos edifícios destinados para fins não residenciais, independentemente do ano de construção ou número de pisos.

As probabilidades de ocorrência a priori $(p)$ referentes a uma subsecção, são dadas por:

$$
\begin{aligned}
& p \text { ('Habitação plurifamiliar') } \equiv p(\mathrm{HP})=\mathrm{HP} / \mathrm{TE}, \\
& p \text { ('Habitação unifamiliar') } \equiv p(\mathrm{HU})=\mathrm{HU} / \mathrm{TE} \text {, } \\
& p \text { ('Núcleo urbano antigo') } \equiv p(\mathrm{NUA})=\mathrm{NUA} / \mathrm{TE} \text {, } \\
& p \text { ('Comércio e serviços') } \equiv p(\mathrm{CS})=\mathrm{CS} / \mathrm{TE} \text {, }
\end{aligned}
$$

com:

HP - número de edifícios plurifamiliares, construídos depois de 1945;

HU - número de edifícios unifamiliares, construídos depois de 1945;

NUA - número de edifícios (exclusiva ou principalmente) residenciais, construídos antes 1945;

CS - número de edifícios predominantemente não residenciais;

$\mathrm{TE}$ - número total de edifícios, relativos à subsecção.

Como é evidente, a soma das quatro probabilidades tem de ser igual a 1. Contudo, alguns dos índices (nomeadamente MFB, SFB e AUN) não são directamente extraídos dos dados estatísticos. Por exemplo, estes dão-nos o número de alojamentos plurifamiliares e o número de edifícios construídos depois de 1945, mas não o número de edifícios plurifamiliares construídos depois de 1945. Assim, foi adoptado o seguinte algoritmo para o processamento das probabilidades a priori:

1. Compute $p(\mathrm{CS})=\mathrm{CS} / \mathrm{TE}$

2. If

$$
\begin{aligned}
& \quad p(\mathrm{CS})>0,8 \\
& \text { then } \\
& \quad p(\mathrm{CS})=1, p(\mathrm{HP})=p(\mathrm{HU})=p(\mathrm{NUA})=0 \\
& \text { else } \\
& \quad p(\mathrm{CS})=0
\end{aligned}
$$

3. If

$$
p(\mathrm{CS})=0
$$

then

$$
p(\mathrm{NUA})=\mathrm{NUA} / \mathrm{TE}
$$




$$
\begin{aligned}
& p(\mathrm{HP})=\left(\mathrm{HP}_{\mathrm{t}}-\alpha \mathrm{NUA}\right) / \mathrm{TE} \\
& p(\mathrm{HU})=\left(\mathrm{HU}_{\mathrm{t}}-\beta \mathrm{NUA}\right) / \mathrm{TE}
\end{aligned}
$$

com:

$\mathrm{HP}_{\mathrm{t}}$ - número de habitações plurifamiliares;

$\mathrm{HU}_{\mathrm{t}}$ - número de habitações unifamiliares.

Os parâmetros $\alpha$ e $\beta(\alpha+\beta=1)$ dizem respeito aos edifícios antigos que são pluri e unifamiliares, respectivamente. Para obter estes resultados, tendo em atenção que não havia uma correlação significativa entre as variáveis, utilizou-se: $\alpha=\beta=0,5$.

As imagens urbanas e as quatro probabilidades a priori constituem a base da aplicação do classificador de Bayes. Estas probabilidades permitem discriminar quatro classes urbanas (Comércio e Serviços, Núcleo Urbano Antigo, Habitação Plurifamiliar, Habitação Unifamiliar) que, devido às suas respostas espectrais semelhantes seriam mal classificadas pelo método . Os usos, 'Indústria' e 'Grandes Equipamentos Urbanos' são, à semelhança da 'Praia' e dos 'Grandes Equipamentos Não Urbanos', obtidos no próximo passo de classificação, recorrendo ao PDM e a regras de pós-classificação.

As áreas de treino (necessárias à aplicação dos dois classificadores) foram delimitadas sobre uma composição colorida, a qual oferecia uma adequada discriminação visual de todos os usos. Esta composição foi obtida da seguinte forma: em primeiro lugar foi criada uma primeira composição colorida utilizando as bandas ETM+ 7, 4 e 1 atribuídas, respectivamente, aos canais R (Red), G (Green) e B (Blue) ${ }^{4}$; de seguida, as imagens dos canais RGB foram convertidas para o espaço de cor I (Intensity - intensidade), H (Hue - tonalidade) $S$ (Saturation - saturação) ${ }^{5}$, passando-se a ter três novas bandas correspondentes à intensidade, tonalidade e saturação; depois a imagem relativa à intensidade foi substituida pela banda pancromática do Landsat (15m resolução espacial), a qual, conjuntamente com as outras duas bandas (tonalidade e saturação), foi convertida novamente para o sistema $R G B$, dando origem a uma nova composição colorida com 15 metros de resolução espacial.

\section{Aplicação das regras de pós-classificação}

A última fase envolve a aplicação de regras bastante específicas para reclassificar alguns pixels que tenham sido atribuídos a classes erradas nas fases ante-

4 As imagens digitais são tipicamente visualizadas através de composições coloridas aditivas, utilizando três cores primárias: encarnado (Red), verde (Green) e azul (Blue). Este sistema de visualização é conhecido por RGB, sendo bastante utilizado no processamento digital de imagens para visualizar composições coloridas arbitrárias, em cor verdadeira ou falsa cor.

5 Outro dos sistemas de cor é o que utiliza a intensidade (Intensity), a tonalidade (Hue) e a saturação (Saturation) para definir uma cor. Neste sistema (IHS) a intensidade corresponde ao brilho de uma cor, a tonalidade refere-se ao comprimento de onda dominante, ou médio, da luz que contribui para a cor e a saturação especifica a pureza de uma cor relativamente ao cinzento. 
riores e que possam ser corrigidos com o uso de regras contextuais e o conjunto de informação auxiliar disponível (rede viária e planta de ordenamento do PDM). Neste contexto, foram consideradas quatro classes de uso: 'Vias', 'Praia', 'Indústria' e 'Equipamentos Desportivos' (uma subclasse dos grandes equipamentos). A rede viária, como já foi anteriormente referido, estava disponível em formato digital e as restantes classes resultam da informação disponível no PDM ou, na ausência desta, das seguintes regras contextuais: i) Praia-pixels que, embora pertencendo à área urbana (valor 1 na máscara urbana intermédia), não foram classificados em nenhuma das classes urbanas e que estão situados a menos $200 \mathrm{~m}$ da linha de costa (limite estabelecido por lei que define o domínio público hídrico); ii) Indústria - pixels classificados como urbanos (valor 1 na máscara urbana final), mas assinalados como indústria na planta de ordenamento do PDM; iii) Equipamentos Desportivos - pixels classificados como mato ou solo a nu, fazendo parte de uma região homogénea com uma área e um perímetro típicos dos campos de futebol e ténis e que distem menos de $500 \mathrm{~m}$ da estrada mais próxima. Para este caso ainda se confrontaram os dados com a planta de ordenamento do PDM, com o intuito de averiguar se este acrescentaria algo mais à classificação. No entanto, no caso de Oeiras, esta planta é composta por classes abrangentes, de modo que não foi possível optimizar a utilização desta informação. Os restantes grandes equipamentos foram retirados da classe 'equipamentos existentes' da planta de ordenamento do PDM.

Todas as classes apuradas foram então integradas num mapa de classificação final mediante a aplicação de um algoritmo que assenta no pressuposto que uma classe não se pode sobrepor a outra já atribuída, redundando este facto na seguinte ordem de operações:

A classificação dos pixels é levada a efeito com base numa perspectiva classe a classe, sendo preconizada da classe com maior nível de confiança para aquela com menor nível de confiança, nomeadamente: 1) Vias (retiradas directamente da rede viária); 2) Água (retirada da máscara água/não água); 3) Comércio e Serviços e Núcleo Antigo (obtidos através do classificador de Bayes); 4) Grandes Equipamentos (resultantes do PDM e/ou regras contextuais, incluindo os equipamentos desportivos) e Praia (resultante da máscara urbana intermédia e regras contextuais); 5) Indústria (resultante da máscara urbana final e do PDM); 6) Outras classes urbanas (obtidas através do classificador de Bayes) e 7) Outras classes não urbanas (obtidas através do método MV).

O mapa resultante desta operação foi então sujeito a uma avaliação visual pós-processamento, com base na planta de ordenamento do PDM. Considerava-se, por exemplo, que existindo neste plano uma classe denominada indústria existente, se ela coincidisse com um espaço classificado como urbano então este último teria sido alterado para industrial. Tal não aconteceu pois as classes da planta de ordenamento revelaram-se demasiado generalistas, não beneficiando em nada a classificação final. A título de exemplo refira-se um espaço industrial situado a Nordeste na área de estudo que, por estar incluído no tecido urbano e instalado num edifício de características em tudo idênticas aos destinados à 
habitação, foi classificado como tal. Esperava-se que o PDM se reportasse àquele lugar como indústria existente, mas ao invés, apresenta-se como urbano existente, validando portanto, a classificação do modelo.

\section{VALIDAÇÃO DOS RESULTADOS}

Resta aferir a validade da metodologia utilizada, o que paradoxalmente, apesar de ser o último procedimento, acaba por se assumir como um dos mais importantes.

Visto estar disponível para a área de estudo a cartografia de uso e ocupação do solo obtida através da interpretação de fotografia aérea vertical (fig. 3) e considerando que por muito correctos que sejam os métodos de recolha de amostras estes podem sempre distorcer os factos, optou-se por uma verificação exaustiva, pixel-por-pixel, de toda a imagem.

Como primeira abordagem, comparou-se a realidade do terreno (fig. 3b) com os resultados obtidos pelo método desenvolvido e pelos classificadores paramétricos tradicionais, nomeadamente, o da mínima distância com distâncias normalizadas (fig. 3c) e da máxima verosimilhança (fig. 3d).

Observando os resultados apresentados pelos classificadores testados face à exactidão global ressalva a superior prestação do algoritmo desenvolvido (70,5\%, que representam um ganho de 33\%). Registou-se um certo equilíbrio entre os da mínima distância $(37,8 \%)$ e máxima verosimilhança $(36,5 \%)$, com uma ligeira vantagem para o primeiro, face ao carácter assimétrico da distribuição dos dados.

\section{CONCLUSÃO}

O método proposto melhorou a exactidão global (superior a 97\%) das classes onde havia informação estatística disponível, nomeadamente as classes 1, 2, 5, 8, 9 e 13. De referir ainda que a classe 5 (Rede Viária) tem um resultado de $100 \%$, porque já existia em formato digital, tendo-se procedido apenas à sua conversão de vectorial para matricial. Por fim, resta referir que o classificador desenvolvido permite identificar, com relativa fidelidade, classes que são «invisíveis» para os satélites (ex. comércio e serviços).

Analisando os resultados numa perspectiva classe a classe (Quadro III), verifica-se que, com o método proposto, se obtêm melhores resultados, com a excepção das classes 4 (Mato) e 7 (Indústria). 

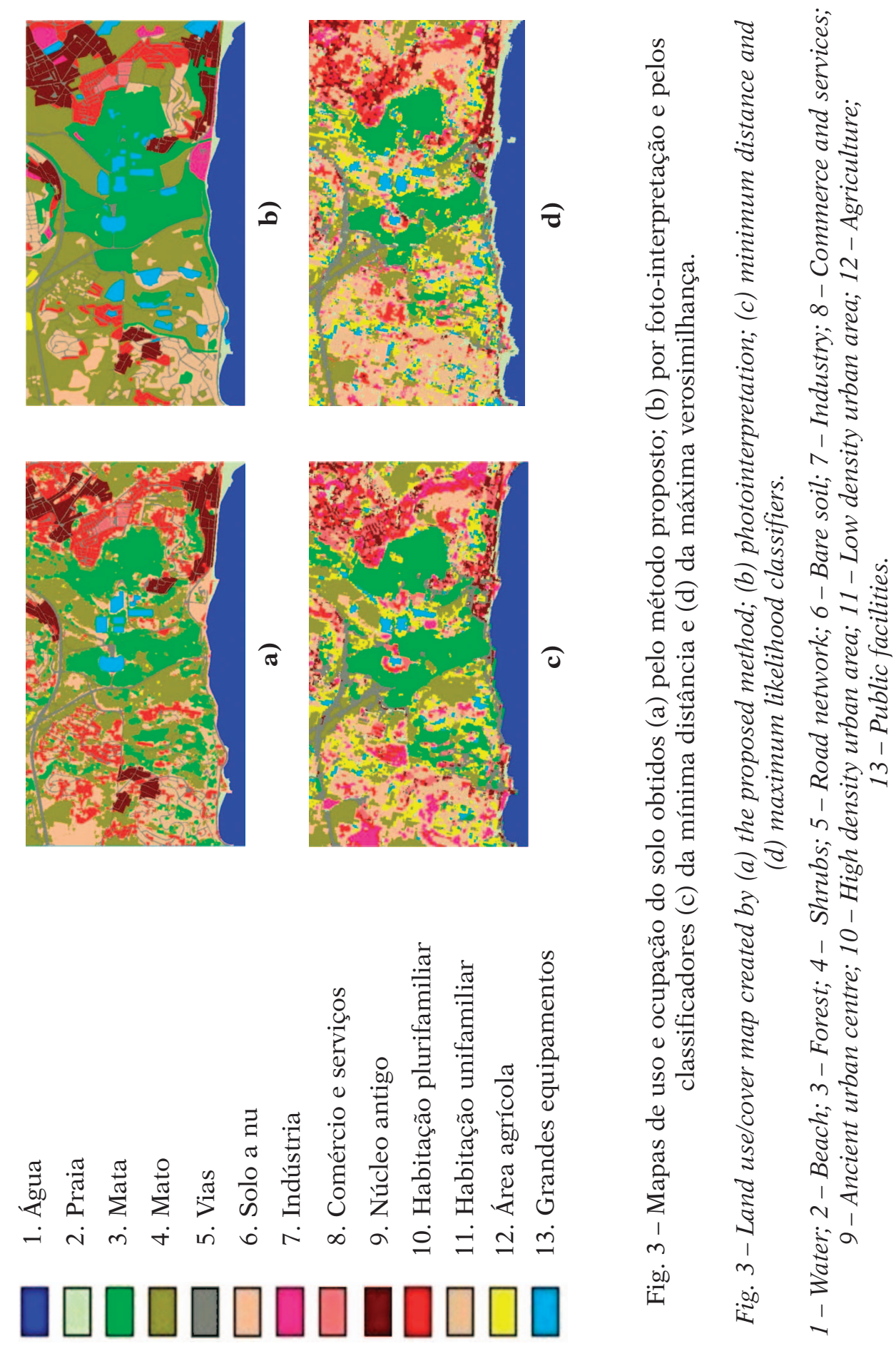
Quadro III - Exactidão global obtida pelo método proposto e pelo classificador da mínima distância para cada uma das classes

Table III - Global accuracy achieved by the proposed method and the minimum distance classifier for each class

\begin{tabular}{lcc}
\hline \multirow{2}{*}{ Classes } & \multicolumn{2}{c}{ Exactidão Global } \\
\cline { 2 - 3 } & Mínima Distância & Método Proposto \\
\hline 1. Água & 98,5 & 99,9 \\
2. Praia & 12,8 & 99,0 \\
3. Mata & 13,4 & 75,0 \\
4. Mato & 84,6 & 75,9 \\
5. Vias & 26,8 & 100,0 \\
6. Solo a nu & 14,8 & 21,7 \\
7. Indústria & 3,6 & 0,0 \\
8. Comércio e serviços & 2,0 & 98,5 \\
9. Núcleo antigo & 25,7 & 98,9 \\
10. Habitação plurifamiliar & 23,0 & 39,3 \\
11. Habitação unifamiliar & 35,4 & 54,8 \\
12. Área agrícola & 0,5 & 34,2 \\
13. Grandes equipamentos & 24,6 & 97,3 \\
\hline
\end{tabular}

\section{BIBLIOGRAFIA}

Achen, M. (1992) - Landsat TM Data for Municipal Environment Planning. Studies of Vegetation Indices on Urban Areas. Proceedings of the XVII ISPRS Congress, Washington (USA), vol. 19: 80-91.

Caetano, M.; Santos, J. P.; Navarro, A. (1997) - Uma Metodologia Integrada para Produção de Cartas de Uso do Solo Utilizando Imagens de Satélite e Informação Geo-referenciada não Espectral. Cartografia e Cadastro, 6: 71-78.

Gong P.; Howarth, P. J. (1990) - The Use of Structural Information for Improving Land-Cover Classification Accuracies at the Rural-Urban Fringe. Photogrammetric Engineering \& Remote Sensing, 56: 67-73.

JaYAMANNA, S. B. (1996) - Relation Between Social and Environmental Conditions in Colombo, Sri Lanka and the Urban Index Estimated by Satellite Remote Sensing Data. Proceedings of the XVIII ISPRS Congress, Austria.

Martin, L.R.G.; Howarth, P. J.; Holder, G. (1988) - Multispectral Classification of Land Use at the Rural-Urban Fringe Using SPOT Data. Canadian Journal of Remote Sensing, 14: 72-79.

Mesev, T.; Longley, P.; Batty, M. (1996) - RS/GIS and the Morphology of Urban Settlements. In P. Longley; M. Batty (Eds.) Spatial Analysis: Modelling in a GIS Environment, John Wiley \& Sons: $123-148$.

Mesev, T. (1998) - The Use of Census Data in Urban Classification. Photogrammetric Engineering \& Remote Sensing, 64: 431-438. 
SAdler, G. J.; Barnsley M. J. (1990) - Use of Population Density Data to Improve Classification Accuracies in Remotely-Sensed Images of Urban Areas. Proceedings of the First European Conference on Geographical Information Systems (EGIS'90), Amsterdam (The Netherlands), EGIS Foundation, Utrecht: 968-977.

Weber, C.; Hirsch, J. (1992) - Some Urban Measurements from SPOT Data: Urban Life Quality Indices. International Journal of Remote Sensing, 13: 3251-3261.

Welch, R. (1982) - Spatial Resolution Requirements for Urban Studies. International Journal of Remote Sensing, 2: 139-146. 